\title{
Cartas inéditas de Graciliano Ramos: Estilo, amizades, bastidores da criação literária e da história
}

\author{
Graciliano Ramos' unpublished letters: \\ Style, friendships, backstage of the literary creation and history
}

Ieda Lebensztayn*

Universidade de São Paulo - São Paulo - São Paulo - Brasil

$\diamond$

\begin{abstract}
Resumo: Este artigo traz uma apresentação da correspondência inédita de Graciliano Ramos: Ativa, Passiva e De Terceiros. Reunidas em livros tão só as cartas do escritor trocadas com familiares, em especial com Heloísa, com um amigo e com dois tradutores argentinos, demandam atenção os diálogos epistolares com outros intelectuais, escritores, tradutores, e também com editores. Venho coligindo esse material, presente no Arquivo Graciliano Ramos do IEB-USP e disperso em livros, periódicos, arquivos e sites, com vistas à publicação de um volume anotado da correspondência. As cartas possibilitam conhecerem-se melhor as circunstâncias históricas vividas pelo escritor, suas relações afetivas e intelectuais, reflexões sobre os romances e projetos literários. Com seu estilo, que inclui autoironia e ternura, elas revelam o rigor ético e estético do romancista. Assim, meu propósito é ampliar a compreensão sobre suas realizações literárias e contribuir para os estudos de epistolografia.
\end{abstract}

Palavras-chave: Graciliano Ramos; Epistolografia; Literatura brasileira; Arquivos de escritores; Correspondência

\begin{abstract}
This paper provides a presentation of unpublished letters by Graciliano Ramos: Active, Passive and From Others. As only the letters exchanged with the writer's family, in especial with Heloísa, with a friend and two Argentines translators were collected in books; the epistolary dialogues with other intellectuals, writers, translators, and editors demand attention. I have been collecting this material, which is in Graciliano Ramos' Archive of IEB-USP and dispersed in books, journals, archives and sites, towards the publication of an annotated volume of the correspondence. The letters allow us to understand better the historical circumstances experienced by the writer, his affective and intellectual relationships, his reflections about the novels and literary projects. With his style, which includes self-irony and tenderness, the letters reveal Graciliano's aesthetic and ethical rigor. Thus, my purpose is to broaden the understanding of his literary achievements and to contribute to the epistolography studies.
\end{abstract}

Keywords: Graciliano Ramos; Epistolography; Brazilian literature; Writers' archives; Correspondence

\section{A correspondência de Graciliano Ramos}

Passados vinte e sete anos da morte de Graciliano Ramos, a editora Record/MPM-Comunicações publicou em 1980 o volume Cartas, contendo a correspondência do escritor com um amigo, Joaquim Pinto da Mota Lima Filho, e com familiares: Maria Amélia Ferro Ramos, a mãe; Sebastião Ramos de Oliveira, o pai; Leonor, Otacília e Marili Ramos, irmãs; Heloísa Medeiros, a noiva das "cartas de amor", depois Heloísa de Medeiros Ramos, esposa (também referida como Ló, d. Ló, Sinha Ló e Mamãe); Luís Augusto de Medeiros, cunhado; Júnio, Clara (Clarita, Lilita), Luiza (Lulu) e Ricardo Ramos (Tatá), filhos. O livro traz Nota de abertura escrita por Heloísa Ramos, seleção de ilustrações e notas feitas pelo escritor James Amado, irmão de Jorge e genro de

\footnotetext{
* Agradeço à FAPESP e ao IEB-USP o apoio para a realização de meu pós-doutorado.
} 
Graciliano (casado com Luiza). Essa edição especial, com o retrato traçado por Portinari na capa, reúne 103 missivas do romancista. Em 1992, por ocasião do centenário do escritor, a editora Record lançou a sétima edição, acrescidas nove cartas. E tal edição de 112 cartas foi relançada em 2011.

Conforme Heloísa Ramos esclarece na Nota, trazia a público então, em 1980, a "correspondência íntima" do marido, que deveria completar-se com "cartas a amigos, escritores, críticos, editores etc." (Ramos, 1980). Solicitando que cópias de mensagens de Graciliano lhe fossem enviadas, ela sublinhava o quanto essa tarefa de reunir a correspondência era necessária e difícil. Tal percepção de Heloísa vale até hoje: se, na ocasião, ela declarava que era "tempo de deixar o próprio Graciliano revelar suas relações com o cotidiano e as pessoas com as quais mais de perto conviveu", persiste o interesse e a busca de leitores e estudiosos por fontes documentais dos diálogos do escritor com outros intelectuais. Foram tão só publicadas, em 2008, pela Editora da Universidade Federal da Bahia (EDUFBA), Cartas inéditas de Graciliano Ramos a seus tradutores argentinos Benjamín de Garay e Raúl Navarro.

Assim, sabe-se ter sido Heloísa Ramos a principal interlocutora das cartas: com a esposa Graciliano partilhou projetos e inquietações. Ao mesmo tempo, os leitores, instigados pelas próprias palavras de Heloísa na apresentação das Cartas, indagam pelos diálogos epistolares do romancista com outros amigos, escritores, críticos, editores, tradutores. Salta aos olhos a escassez de publicações dessas cartas trocadas com outros intelectuais, mesmo levando em conta as dificuldades da vida de Graciliano, a mudança de Alagoas para o Rio de Janeiro forçada pela prisão em março de 1936.

Então, contando com a confiança de d. Luiza Ramos Amado, filha de Graciliano, tenho-me dedicado à organização desta correspondência inédita. A maior parte dos documentos consta do Arquivo Graciliano Ramos, doado por Heloísa Ramos em 11 de outubro de 1980 ao Instituto de Estudos Brasileiros da Universidade de São Paulo, IEB-USP: incluem-se aí as Séries Correspondência Ativa e Correspondência Passiva de Graciliano e cartas De Terceiros.

Junto aos manuscritos das cartas para Heloísa, para outros familiares e para Joaquim Pinto da Mota Lima Filho, estas publicadas no volume da Record, verifiquei, no Arquivo, 45 inéditas da correspondência ativa. Quanto à correspondência passiva de Graciliano, não há publicação em livro; constam 82 documentos no IEB. A tarefa de reunir a correspondência passiva, demandando o empenho por decifrar diferentes manuscritos, possibilita saber de pessoas que dialogaram com o romancista, de maneira tão só cordial ou afetiva, e compreender melhor contextos histórico-literários. Embora constituído por apenas 15 cartas, o conjunto da correspondência de terceiros que consta do IEB também traz matéria de grande interesse, conforme apontarei a seguir.

O próprio trabalho com as cartas do Arquivo resultou no propósito de oferecer ao público uma reunião mais completa da correspondência inédita de Graciliano. Procedi, pois, ao levantamento e ao registro de cartas dispersas em livros, periódicos, sites (do "Projeto Portinari”, da Fundação Biblioteca Nacional etc.) e em arquivos como a Fundação Casa de Rui Barbosa, a Biblioteca Nacional, o Acervo de Escritores Mineiros da UFMG, o Arquivo Público de Alagoas, o Arquivo Edgard Leuenroth da UNICAMP; encontrei 43 documentos da correspondência ativa de Graciliano, 14 da passiva e 10 de terceiros.

Ante a riqueza desses documentos pertencentes ao Arquivo Graciliano Ramos do IEB-USP e dispersos em livros, periódicos, sites e arquivos, delineou-se meu objetivo de reuni-los para uma publicação mais completa, uma edição crítica com notas. Entendem-se aqui as notas segundo o conceito de "belle note" proposto por Colette Becker (1984): voltadas para elucidar o contexto das cartas, oferecem informações histórico-literárias e dados biobibliográficos dos correspondentes e de outras pessoas referidas.

Acompanhada da bibliografia de crítica genética, de epistolografia e historiografia literária e de obras centradas na história de editoras e de intelectuais brasileiros, tenho elaborado notas biobibliográficas sobre os interlocutores do escritor e notas explicativas sobre os contextos histórico-literários. São duzentas e nove cartas inéditas e duzentos e vinte e oito nomes de pessoas e instituições nelas referidos. As pastas de recortes de periódicos do Arquivo Graciliano Ramos do IEB contêm um material bastante útil para a composição de notas. E tenho-me embrenhado também na Hemeroteca Digital Brasileira, da Biblioteca Nacional, a partir de cujos periódicos é possível reconstituírem-se momentos significativos da história, da literatura, da crítica. Ressalto, ainda, as Memórias de um escritor, v. 1, de Nélson Werneck Sodré (1970): apresenta três cartas de Graciliano ao autor e traz comentários a respeito de pessoas e de fatos da época, esclarecedores sobre os contextos.

Entendo que, complemento necessário do livro Cartas publicado pela Record, o volume anotado da correspondência inédita de Graciliano Ramos - Ativa, Passiva e De Terceiros - deve igualmente ser organizado conforme critérios cronológicos e espaciais. Apresentarei aqui algumas cartas inéditas, as quais agrupei em três períodos, acompanhando circunstâncias da vida do escritor. 


\section{De 1905 a 1915, com destaque para a viagem do jovem Graciliano ao Rio de Janeiro, em 1914-5}

Há cartas para o pai e para as irmãs Leonor, Otília e Otacília, ainda não publicadas. Curiosamente, uma delas é de Graciliano aos doze anos, menino que pede a bênção ao pai e aconselha as irmãs a estudarem.

Basta um relancear de olhos para surpreender-se o tom bem-humorado, irônico e autoirônico de Graciliano ao escrever, de um de seus endereços no Rio (Largo da Lapa $-110-1^{\circ}$ andar), a 21 de novembro de 1914, para o amigo José Tobias Filho, que se tornara então intendente de Palmeira dos Índios. Porém, já se vê que a autoironia guardava a melancolia do moço apreensivo por um bom emprego:

O pior é que, em minhas cavações, não tenho conseguido arranjar um emprego em nenhum jornal. Imagine um homem como eu reduzido ao mísero papel de suplente de revisão! É uma injustiça! Esses jornalistas idiotas não sabem compreender o valor de um indivíduo que, apesar de modesto, se pode gabar de ter sido professor em Palmeira dos Índios!.. Um professor que dava aulas, diante de um bando [de] moças, vestido de pijama... (RAMOS, 1914)

Significativamente, ele também expressa em tal carta saudades de Palmeira dos Índios e desconfiança ante as modernidades da civilização. Realçando a beleza da paisagem alagoana, lamenta que existissem em meio a ela "horrorosos automóveis": "Detesto os automóveis: cheiram muito a civilização".

Mas principalmente demanda atenção uma carta de 27 de abril de 1915, para a "impagável Otacília": maravilhado, ele descreve à irmã seu "magnífico passeio" junto com amigos, entre eles Joaquim Pinto Mota Lima, no morro do Castelo, no Rio de Janeiro. Como na já publicada carta a Leonor Ramos, também do Rio, de 20 de março de 1915, usa nesta missiva inédita a expressão "linhas tortas" para cobrar da irmã notícias dos textos que enviava para o Jornal de Alagoas.

\section{De setembro de 1915 até a prisão, em março de 1936}

Nesse período, Graciliano Ramos escreveu Caetés (publicado em 1933), S. Bernardo (1934) e Angústia (1936). Casou-se com Maria Augusta (1915), enviuvou (1920) e se casou com Heloísa (1928); teve oito filhos. Viveu em Palmeira dos Índios, cidade da qual foi prefeito (1928-30), e em Maceió, onde trabalhou como diretor da Imprensa Oficial e depois da Instrução Pública.
Se são raras as referências escritas de Graciliano diretamente à sua imensa dor pela morte da esposa Maria Augusta de Barros, uma delas está em carta de Palmeira dos Índios, de 20 de dezembro de 1920, para Rodolfo Mota Lima. Graciliano agradece ao amigo as "boas palavras" enviadas quando da morte da companheira, aludindo àqueles "dias terríveis". A 23 de novembro a esposa falecera, deixando quatro filhos: Márcio, Júnio, Múcio e Maria Augusta, que nascera então.

O "caro Rodolfo", destinatário da carta, é um dos irmãos de Joaquim Pinto Mota Lima, todos amigos de Graciliano. O leitor de Infância há de lembrar-se da transfiguração dos Mota Lima no início de "Os astrônomos": quase analfabeto aos nove anos, o menino Graciliano se via inferior a eles, seus vizinhos, garotos limpos e risonhos, frequentadores de boa escola, os quais julgava perfeitos.

E endereçada a outro irmão de Joaquim Pinto Mota Lima, todos residindo no Rio, é uma carta também de Palmeira, de 15 de julho de 1922: ao "meu bom Doca", Pedro Mota Lima. Graciliano se mostra surpreso ao saber que o amigo havia sido detido por causa do movimento revolucionário tenentista de 1922 no Rio de Janeiro. A correspondência com Pedro Motta Lima (1897-1966), o Doca, contribui para conhecer-se melhor esse intelectual: um dos divulgadores, no Rio, dos Relatórios de Graciliano prefeito, publicou, entre outras obras, o romance Bruhaha (1929) e foi diretor e redator de diversos jornais vinculados ao Partido Comunista.

A 2 de outubro de 1931, Aloísio Branco, poeta da revista alagoana Novidade que foi ao Rio de Janeiro com Jorge de Lima, escreveu a Graciliano perguntando-lhe se recebera as provas tipográficas de Caetés. O poeta encontrava-se na Livraria Católica, de Augusto Frederico Schmidt, junto de Rômulo Ferreira de Castro, secretário deste. Num tom de ironia bem-humorada, a resposta de Graciliano Ramos indica seu afeto pelo jovem Aloísio, intelectual entregue à literatura, religioso e avoado. Como este não enviara seu endereço do Rio, obrigara o romancista a adivinhar a "região intermediária" em que se achava o destinatário, ou seja, a Livraria Católica. Ironizando o fato de a velocidade moderna e o linotipo servirem a finalidades católicas, Graciliano se ri do temor do jovem provinciano ante a modernidade carioca, cobralhe por fim um abraço e desconfia das promessas do editor Schmidt. A carta é reveladora do início da escrita de $S$. Bernardo (que veio a público em 1934): desanimado porque demoravam a chegar as provas tipográficas de Caetés, Graciliano abandonara "os trabalhos rurais" e os estudos sobre gado em que estava envolvido.

Da correspondência passiva de Graciliano, acompanhando justamente essa demora da publicação de Caetés, salientam-se várias missivas de Rômulo de 
Castro, secretário da Schmidt Editora, uma delas com uma nota do próprio editor e poeta Augusto Frederico Schmidt: datam de 1930 e de 1931.

Sobre um projeto de contrato para editar Caetés destaca-se uma carta de Graciliano, de Maceió, do dia 3 de janeiro de 1933, aos "Ilmos Srs. Adersen-Editores", do Rio de Janeiro. O romancista menciona o amigo Valdemar Cavalcanti como mediador da negociação e solicita alterações no contrato. Como se percebe, esta faz parte de um conjunto de cartas e textos impressos que, segundo entendo, articulados, podem contribuir para se conhecerem melhor a história da publicação de Caetés, obra de estreia de Graciliano, e a história das editoras no Brasil. A Adersen Editores era uma firma pequena, fundada em 1931, cujo nome decorria da fusão dos nomes de seus proprietários, que depois, separados, seguiriam importantes caminhos como editores: Adolfo Aizen e Sebastião de Oliveira Hersen.

Nesse contexto, importa ressaltar a Correspondência de terceiros que consta do Arquivo Graciliano Ramos: traz, por exemplo, a mediação de Valdemar Cavalcanti junto a Adersen-Editores e à Companhia Editora Nacional pela publicação de Caetés, enquanto a editora Schmidt demorou a produzi-lo. (O romance saiu finalmente em dezembro de 1933.) Essas cartas são fontes para se saber mais das relações de sociabilidade e de afeto de Graciliano, do início de sua carreira literária e da história do livro no Brasil. Deixam ver bastidores da publicação de Caetés, com destaque para a amizade de Valdemar Cavalcanti por Graciliano, que continuaria no Rio de Janeiro, a honestidade do editor Hersen, os obstáculos do mercado editorial brasileiro, incipiente nos anos 1930. A 13 de abril de 1933, Sebastião de Oliveira Hersen, um dos donos da Adersen Editores, dirigiu-se a Valdemar Cavalcanti, amigo de Graciliano: declara toda a sua aflição, premido por dificuldades financeiras, empenhado por publicar Caetés e S. Bernardo.

Numa carta de 8 de março de 1934, Graciliano agradece ao folclorista viçosense Aloysio Villela um artigo centrado em Caetés. Comenta o romance que lançaria naquele ano, S. Bernardo, e se recorda do gosto literário na Viçosa de 1905, evocando a figura de Mário Venâncio, referência marcante também em Infância.

Em outra, escrita de Maceió para Jorge Amado, em abril de 1934, Graciliano brinca que ele próprio, José Lins do Rego e os rapazes Alberto Passos Guimarães, Aurélio Buarque e Aloísio Branco, "esta cambada toda", faziam "uma literatura medonha", nos cafés e no Jornal de Alagoas (Amado, 2012). Trata-se do grupo da revista Novidade: chamado de "o velho Graça", desde os anos 1930 em Maceió, Graciliano gostava do convívio com intelectuais jovens. Se sabemos que o silêncio era necessário para a escrita artística de Graciliano, ao mesmo tempo esse vínculo com escritores moços permite relativizar a imagem do romancista como homem isolado e seco. A carta a Jorge Amado, uma dedicatória de Caetés, revela a expectativa de Graciliano quanto à publicação de S. Bernardo, no prelo, e a insatisfação porque a escrita de seu novo romance [Angústia] "encrencara" logo no início.

\section{Período da prisão (mar. 1936-jan. 1937) e desde a saída da cadeia, no Rio de Janeiro, até 1952, ano da viagem para a Tchecoslováquia e a União Soviética}

Nesse tempo, Graciliano Ramos escreveu: $A$ terra dos meninos pelados (1937), Vidas secas (1938), Pequena história da República (1940), "Mário", do romance coletivo Brandão entre o mar e o amor (1942), Histórias de Alexandre (1944), Infância (1945), Insônia (1947), Memórias do cárcere (publicação póstuma, 1953), Viagem (1954), crônicas (reunidas postumamente em Linhas tortas, em Viventes das Alagoas, 1962, e em Garranchos, 2012). E traduziu: Memórias de um negro, de Booker Washington (1940), e A peste, de Albert Camus (1950). Em 1957, saiu a antologia organizada por Graciliano, Contos e novelas.

Ao preparar essa Seleção de contos brasileiros, em busca da literatura das várias regiões do país, o romancista escreveu a alguns críticos, a academias de letras do país e a diretorias de instrução pública. Conforme explica no prefácio da antologia, em geral não lhe responderam ou lhe deram respostas ásperas, como a alegação de que não cuidavam de tais "tolices", apenas de assuntos graves.

Documentos da correspondência ativa e passiva de Graciliano se centram no pedido e na indicação de contos para a coleção. As cartas trocadas com o crítico Wilson Martins, em 1944 e 1945, tratam da sugestão de contos paranaenses a serem selecionados. Graciliano aguarda de Carlos de Gusmão, após 16 de abril de 1945, escritos de Alagoas, e a resposta do conterrâneo vem a 21 de maio do mesmo ano. Também a correspondência com Paulo Augusto de Figueiredo (à época, redator de Oeste, de Goiás, e da revista Cultura Política), em 1945, era movida pelo empenho de Graciliano em preparar a Seleção de contos brasileiros. Sua dedicação à antologia se acompanhou da preocupação quanto à carência do país em termos de uma tradição cultural, literária. E a Seleção traz indícios de seu gosto literário, instigando o leitor a conhecer os contistas escolhidos.

O gosto literário de Graciliano também se deixa ver em carta a Moacir Arcoverde, Secretário de Divulgação e Propaganda do Partido Comunista do Brasil do Paraná e sócio da editora Guaíra, de Curitiba. Junto com a carta, ele encaminha um prefácio a Neblina, livro de contos 
do pernambucano José Carlos Cavalcanti Borges, e se declara feliz por colaborar para a publicidade desse escritor e também do romancista Oswaldo Alves. O prefácio, "Justificação de voto" (incluído em Linhas tortas), destaca o conto epistolar "Coração de d. Iaiá", vencedor do concurso de contos de Dom Casmurro, cujo júri Graciliano integrou. Neblina saiu pela editora Guaíra, em 1940, bem como Um homem dentro do mundo, de Oswaldo Alves, romance referido na carta. Tanto confiava na literatura dos dois escritores, Graciliano os incluiu na sua Seleção de contos brasileiros: José Carlos Cavalcante Borges, com "Felicidade", e Oswaldo Alves, com "Dorme, meu filho".

Se nos anos 1940 houve esse interesse pelos contos, já desde 1935 Graciliano observava que os romances de seus pares nordestinos vinham perdendo o vigor artístico. Em carta a Nelson Werneck Sodré, de outubro de 1942, comenta que publicara no início do ano, na Argentina, um artigo sobre a decadência do romance brasileiro, lamentando que os novos livros dos amigos se afastassem de Banguê, Jubiabá e João Miguel. O artigo, "Decadência do romance brasileiro", cujo manuscrito data de 20 de outubro de 1941, saiu também na Nueva Gazeta uruguaia em dezembro de 1941 e em Literatura em 1946 (Ramos, 1941). E, em carta a Cyro dos Anjos de março de 1938, Graciliano afirma que o romance nacional morria, revelando, num tom irônico feito de melancolia, que a situação editorial no país era bastante difícil.

Dos anos 1940, destaca-se também uma carta a Luís Carlos Prestes, expressando solidariedade a ele e comunicando-lhe que se organizava a Comissão de Defesa do Mandato do Senador Prestes. Embora não esteja registrada a data, Prestes foi o único senador eleito do Partido Comunista Brasileiro para a Constituinte de 1946 e teve cassado seu mandato em 1948. Lembre-se que Graciliano se filiou ao Partido Comunista em 1945, a convite de Prestes.

Como se observou, Jorge Amado é um dos escritores cujas cartas trocadas com o escritor alagoano devem ser consideradas. Há duas de 1948 endereçadas a "meu velho Jorge", então em Paris, em que Graciliano trata da tradução de suas obras na Tchecoslováquia e manda recomendações a D. Zélia.

A carta a Caio Prado Júnior, de 1949, é reveladora quanto aos obstáculos para que Graciliano se dedicasse à tarefa de missivista: ele se desculpa pela demora da resposta, motivada "por excesso de trabalho, desorganização, relaxamento". Infere-se que se trata da resposta a um convite para o nome de Graciliano figurar na comissão editorial de uma revista. Graciliano observa que o amigo o sabia livre de cerimônias, tanto que já "estragara" a revista que então fazia [Fundamentos] pondo o seu nome na comissão editorial.
Justamente a correspondência testemunha a vida atribulada do escritor no Rio, acumulado de trabalhos, sem tempo para responder cartas. Ele já o declarava para Serafín Garcia, a 13 de outubro de 1943, ao se desculpar pela demora em enviar ao amigo, tradutor uruguaio de Angústia, uma contribuição para a Antologia do conto social americano:

Justifico a demora por dois motivos. Em primeiro lugar tenho estado cheio de ocupações: além do meu trabalho ordinário, surgiram outros que me levam todo o tempo, e vivo meio doido, porque nem posso dormir direito. As pilhas de papel crescem na mesa, as gavetas estão cheias de cartas, que ficam sem resposta, há pedaços de jornais em toda a parte. Quando Rodolfo Ghioldi esteve aqui em casa, espantou-se: '- Como diabo pode V. trabalhar no meio desta balbúrdia?'. Em segundo lugar estive a esperar que os srs. Livschitz \& Morosoli me dissessem qualquer coisa sobre a edição uruguaia de Angústia. Não disseram. [...] Não sou rico para chamar advogados, meter-me em questões que não provoquei. Enfim, um desastre. (RAMOS, 1943)

A correspondência posterior de Graciliano com Serafín Garcia e com os srs. Livschitz \& Morosoli, da Editorial Independencia, revela que a tradução uruguaia de Angústia saiu, em 1944, e o romancista ficou bastante satisfeito com a apresentação gráfica da edição e com o "admirável" trabalho do tradutor e prefaciador. Incluindo referências a amigos como Jorge Amado e Rodolfo Ghioldi, o diálogo epistolar de Graciliano com Serafín Garcia, tradutor, poeta e contista, merece ser salientado: contém comentários sobre a prosa literária de ambos, reciprocamente admirada.

Existem cartas de Graciliano para diversos editores, nas quais procura negociar a tradução dos romances para várias línguas, acolhendo a demanda dos países: Charles Ofaire (Karl Hofer), representante suíço da Atlântica Editora (1942); Eduardo Mallea, editor e escritor argentino (1943); C. A. Hutchinson, editor, tradutor e professor inglês (1943); L. C. Kaplan, autor da versão de Angústia para o inglês, publicada em 1946 por Alfred A. Knopf, de Nova York, também correspondente do romancista (1944); Sfinx Publishers Ltd., da Tchecoslováquia (1948); Gallimard, da França (1952); etc. Vale notar como os anos 1940 constituíram um momento histórico de especial interesse das editoras estrangeiras por traduzirem a literatura brasileira. E aqui interessa pensar como, garantindo a atenção do público estrangeiro, se configura a força universal da literatura de Graciliano Ramos, fincada na observação da realidade do Nordeste brasileiro.

As cartas a João Condé, a Antonio Candido, a Cassiano Nunes e a Haroldo Bruno sobressaem como "arquivos da criação" (Diaz, 2007; Moraes, 2009). Graciliano relata 
a Condé o nascimento de $S$. Bernardo, que desenvolveu "os crimes e um desastre conjugal" do conto de origem ("A carta"), cortados adjetivos e descrições. Também ao dono dos "Arquivos Implacáveis", de O Cruzeiro, é revelada a ordem de escrita dos capítulos de Vidas secas, a gênese desse romance "desmontável" (evocando aqui a conhecida expressão de Rubem Braga). Já as cartas aos referidos críticos, detendo-se sobretudo na composição de Angústia, confirmam como Graciliano conjugou em seus romances a expressão de dramas morais e a representação crítica de problemas sociais.

Além dos citados Pedro Mota Lima, Rômulo de Castro, Augusto Frederico Schmidt, Wilson Martins, Carlos de Gusmão e Serafín Garcia, destacam-se, da correspondência passiva, os nomes de Erico Verissimo, José Olympio, Alceu Amoroso Lima, Sátva Brandão, Miécio Tati, o governador de Alagoas Álvaro Paes, o escritor baiano Edson Carneiro, o crítico e ficcionista cearense Braga Montenegro. Há alguns cartões: de Otto Maria Carpeaux, Santa Rosa, Candido Portinari. Graciliano recebia também convites de editoras e de Academias de Letras, bem como cartas de admiradores de sua ficção e de candidatos a escritores.

Em carta de Porto Alegre, de 18 de agosto de 1938, o romancista Erico Verissimo, editor da Livraria do Globo, conta que $A$ terra dos meninos pelados sairia antes do Natal, ilustrado por Nelson Boeira Faedrich, que pretendia logo terminar o trabalho. (Com belas ilustrações, o livro veio a público em 1939.) Erico esclarece que a editora não poderia mais assumir compromissos aquele ano e pede paciência, pois não obtivera o pagamento adiantado. Confessa ter ficado satisfeito por saber que Graciliano não desgostara de seu romance Olhai os lírios do campo, ainda mais levando em conta o estado de espírito do amigo quando se encontraram no mês de julho.

Em cartas de 1945, Alceu Amoroso Lima pede ao "Prezado confrade" Graciliano a sua "valiosa contribuição", um artigo de três a seis páginas com um depoimento sobre Georges Bernanos, esse "amigo tão sincero do Brasil e esse grande lutador pela causa da liberdade, da justiça e da verdade". Escreve em nome da Atlântica Editora, da França, que organizava um volume coletivo em homenagem a Bernanos, residente então no Brasil (de 1938 a 1945). Mas o próprio Alceu reconhece que o prazo para o envio do texto era muito curto, provavelmente um dos motivos por que Graciliano não pôde colaborar.

Destaca-se a carta de Sátva Brandão, de Moscou, de julho de 1952: ela relata ao "camarada" Graciliano que o capítulo "Cadeia", de Vidas secas, despertara interesse imediato na redação de Ogoniók - a mais popular revista soviética, cujo nome, Огонёк, significa 'chama', 'faísca'
- e fora muito bem recebido pelos leitores. Filha do intelectual alagoano Octavio Brandão e da poeta Laura da Fonseca e Silva Brandão, comunistas exilados para a Alemanha em 1931 e refugiados na União Soviética, que lutaram durante a Segunda Guerra Mundial, Sátva deixou o Brasil com nove anos e perdeu a mãe em 1942. Na União Soviética, verteu Vidas secas para a língua russa, junto com o marido, Zarém Tchernóv. E a primeira edição, publicada em 1961 pela Editora Estatal de Literatura Artística, de Moscou, foi de 100 mil exemplares. Sátva e Zarém encontraram Graciliano em Moscou em junho de 1952, conforme se lê no capítulo 11 de Viagem, e o romancista sequer acreditava que a versão russa do livro seria publicada. Decerto por configurar esteticamente o drama do vaqueiro e sua família, em sua articulação com o fator economico, Vidas secas foi acolhido pelo público soviético

Já a correspondência com os escritores Ferreira de Castro, José Osório de Oliveira, Joel Serrão e Castro Soromenho mostra a força da literatura de Graciliano aos olhos dos portugueses. Soromenho expressa sua admiração pela integridade e pela arte de Graciliano, a quem considera "o maior romancista moderno de língua portuguesa".

Merece atenção a missiva de 27 de setembro de 1948 de Miécio Tati, reveladora do contexto literário brasileiro de então. Autor do romance Nossa máxima culpa, publicado nesse mesmo ano (e reeditado depois, em 1961, com o título Rio dos afogados), Miécio se queixa de Graciliano e de Carpeaux por haverem ignorado o seu livro. Carpeaux afirmara não existir à época tendência alguma do moderno romance brasileiro.

A correspondência de terceiros possibilita-nos conhecer os percalços enfrentados por Heloísa Ramos quando migrou de Alagoas para o Rio de Janeiro com o propósito de tirar Graciliano da cadeia: a 11 de maio de 1936, ela escreveu do Rio de Janeiro ao irmão, Luis Augusto de Medeiros, relatando-lhe os passos em busca de libertar Graciliano e as negociações com José Olympio para editar Angústia. As cartas de terceiros presentificam também: informações do Padre Macedo sobre o inventário do pai de Graciliano; a preocupação de Benjamin de Garay com a situação do amigo preso; a emoção de Graciliano na viagem a Paris, em 1952; o entusiasmo de Octavio Brandão quando, após os anos de exílio, passou a colaborar no Suplemento Literário do Diário de Notícias, por intermédio de Álvaro Lins, e publicou quatro artigos sobre Graciliano; recordações de um jovem poeta viçosense, Aldebarán Alves de Souza, que encontrou Graciliano no Rio e se impressionou com seu "ar encarquilhado" e de descontentamento e revolta, e, a um tempo, afável, extremamente atencioso para com ele. 


\section{A publicação de cartas inéditas de Graciliano Ramos: alcance hermenêutico}

Como se vê, o estudo das cartas de Graciliano Ramos contribui para uma dimensão vertical, de aprofundamento da compreensão de sua vida e obra. Ao mesmo tempo, abre para a difícil e fecunda tarefa de construir um quebracabeça ilimitado, sempre renovável, fonte de descobertas sobre a sociabilidade do escritor e sobre outros nomes da cultura (brasileira, argentina, uruguaia); e também sobre a história das editoras e dos livros no Brasil, os vários momentos históricos e culturais, os bastidores subjetivos e estilísticos da criação literária.

Pensando-se nos estudos epistolográficos, é pertinente a indagação sobre haver Graciliano Ramos se correspondido prioritariamente com alguém. Ao que tudo indica, a correspondente principal do escritor foi Heloísa e, na juventude, o amigo Joaquim Pinto da Mota Lima: são mais de sessenta cartas para a esposa, catorze para Joaquim Pinto. Também com os pais e irmãs Graciliano se comunicava bastante por cartas.

Não é fácil reconstituírem-se em sua continuidade os diálogos epistolares do escritor. Sequências perguntaresposta encontram-se pouco na correspondência de Graciliano: em especial, com os alagoanos Aloísio Branco e Carlos de Gusmão, com Jorge Amado e, sobretudo, com o uruguaio Serafín Garcia e com alguns representantes de editoras. Se não se recupera a continuidade dos diálogos, em geral por terem sido exíguos - dadas as circunstâncias da vida de Graciliano, a prisão, a mudança forçada de Estado, as dificuldades financeiras e obrigações de trabalho -, por outro lado se depreende como traço da especificidade de sua correspondência a variedade de interlocutores.

Quanto às relações de sociabilidade, nota-se o papel da correspondência para desmistificar a imagem de Graciliano como tão só pessimista e afastado do convívio social. Nos anos 1930, o "velho Graça" tinha proximidade afetiva e intelectual com os jovens escritores alagoanos. E as cartas o provam até poeticamente: no Rio de Janeiro, recém-saído da prisão, enquanto escrevia $A$ terra dos meninos pelados (1937), em cartas a Heloísa mandava lembranças aos "meninos impossíveis" que ainda estavam em Alagoas - Valdemar Cavalcanti, Aurélio Buarque, Diégues Júnior, Barreto Falcão -, chamando-os com afeto de "meninos pelados".

E é vasto o rol de interlocutores que o escritor conheceu após a prisão, quando vivia no Rio. Cartas trocadas com escritores, com editores de livros e de periódicos, com tradutores, intelectuais portugueses e críticos literários tratam de projetos literários, como as publicações dos livros, de traduções, de contos e crônicas na imprensa, da antologia de contos.
Várias missivas, permitindo conhecer melhor a trajetória do autor e o contexto da escrita dos romances, auxiliam o movimento de análise e interpretação da obra. As de 1914, do Rio de Janeiro, carregam as tensões do jovem Graciliano entre saudades de Palmeira dos Índios e recusa de seu ambiente intelectual restrito, atração e desconfiança ante a civilização representada pela Capital Federal, onde buscava um bom emprego. Algumas cartas de 1935 trazem uma atmosfera opressiva, quando se pressentiam os horrores da Segunda Guerra Mundial e do Estado Novo; em várias posteriores a 1937, Graciliano se refere à sua prisão. Cumpre, ainda, atentar para cartas que, como as dirigidas a Nelson Werneck Sodré e a Cyro dos Anjos e a de Miécio Tati, refletem o momento de incerteza, desde 1935 e na década de 1940, quanto ao romance (brasileiro). E esta era a época em que Graciliano passava da ficção às memórias e se dedicou à seleção de contos brasileiros.

Além de fornecer informações sobre o momento histórico e pessoal do escritor, a correspondência traz ponderações do autor sobre a concepção, os significados e limites de sua arte, sobre a crítica. Tais observações interpretativas contribuem para melhor se compreenderem a construção de imagens, a representação crítica da realidade social e a expressão de conflitos subjetivos na obra (Bosi, 1991). Aqui se incluem várias cartas a Heloísa, as dirigidas a Condé, a Antonio Candido, a Cassiano Nunes, já referidas. Ricas de relatos da gênese de textos literários, destacam-se como "arquivos da criação".

Marca estilística das cartas de Graciliano é o emprego da primeira pessoa do singular para referir-se a ações de suas personagens, o que dá a medida de seu empenho a um tempo estético e ético pela criação ficcional. Por exemplo, na carta a Aloísio Branco, de 1931, ante a demora da publicação de Caetés enquanto já compunha S. Bernardo, deixa ver seu desânimo junto com sua entrega à ação de Paulo Honório: "abandonei os trabalhos rurais a que me vinha dedicando". Esse emprego da primeira pessoa nas cartas, identificação do criador com suas personagens, guarda um sentido de ironia, distanciamento crítico do escritor em relação ao mundo, porém de humor também em relação a si próprio, de autoironia. Ser outro significa buscar uma possibilidade de mudança em relação ao lugar-comum, mas também assumir os riscos do processo de criar um mundo ficcional - a autocrítica, a insatisfação com a obra, a incomunicabilidade com o público ou a acolha dele, até a responsabilidade pelas ações de seus personagens. Nesse sentido, sobressai esta passagem da carta de 17 de julho de 1945 para Livschitz \& Morosoli, da Editorial Independencia, que, como se assinalou, publicaram Angústia no Uruguai, com tradução e prefácio de Serafín J. Garcia: 
Enfim os srs. melhor que eu conhecem o gosto do público uruguaio: até hoje nem sei como foram aí recebidos o meu criminoso e o sujeito que deixei enforcado num galho. (RAMOS, 1945)

Ao perguntar pela recepção do romance no Uruguai, Graciliano enfatiza como sua a responsabilidade do "criminoso" Luís da Silva, cujo drama é a um tempo social e moral: o escritor deixa ver a preocupação ética e estética que move sua obra.

Disposição afetiva, interesse intelectual, olhar crítico e humor transparecem na correspondência com o tradutor uruguaio, que condensa traços marcantes do estilo epistolar de Graciliano Ramos e questões centrais do conjunto das cartas. Ele conheceu pessoalmente Serafín J. Garcia em 1941 no Rio de Janeiro, graças à mediação de Jorge Amado, que viveu alguns meses em Montevidéu. Serafín esteve no Brasil com a esposa no final de 1941; o dinheiro para a viagem foi conquista de seu livro de contos Burbujas (1940), premiado pelo Ministério de Instrução Pública do Uruguai. Nas cartas, Graciliano revela sua expectativa por receber livros de Serafín (Burbujas, En carne viva, Asfalto) e depois se confessa compungido com as personagens dos contos. Se expressa comoção, não lhe faltam à pena a autocrítica em relação a seus contos, "uns casos muito vagabundos", nem o olhar crítico frente às demoras na comunicação, decorrentes do seu excesso de trabalho, mas também de desencontros do correio e de portadores de cartas. Com a arma do humor, sua amizade com Serafín lhe concedia liberdade para ironizar a dificuldade dos editores em the pagarem os direitos:

Perguntam-me eles se devem realizar o pagamento e a maneira mais prática de efetuá-lo. Acho que devem, é claro. O mais prático julgo que não representa nenhuma dificuldade e os comerciantes o conhecem muito bem. (RAMOS, 1945b)

Assim, a tarefa de edição de cartas propicia a combinação entre pesquisa em arquivos de escritores, análise de fontes primárias e interpretação literária. $\mathrm{O}$ estudo epistolográfico abre caminho para se conhecerem melhor as circunstâncias históricas vividas pelo escritor, suas relações afetivas e intelectuais, seus projetos e reflexões sobre a ficção, própria e alheia. Dessa forma, permitirá ampliar-se a compreensão sobre as realizações literárias de Graciliano, considerando-se também o estilo das cartas; com sua mescla de autoironia e ternura, sinalizam, mesmo na gratuidade própria do gênero epistolar, o rigor ético e estético de um escritor respeitoso às pessoas e às palavras, com suas singularidades, diferenças.
Neste momento da pesquisa, o total de documentos inéditos de que se tem notícia, incluindo os do Arquivo do IEB e os que estavam dispersos, é de 88 da correspondência ativa, 96 da passiva e 25 de terceiros, dos quais alguns ainda serão buscados. A reunião de documentos, a ser proximamente publicada, integra um caminho cujo horizonte é alargar a compreensão sobre a vida e a obra de Graciliano, bem como conhecer rostos singulares e sua interação com a história coletiva.

\section{Referências}

AMADO, Jorge. Navegação de cabotagem. São Paulo: Companhia das Letras, 2012.

BARROS, Francisco Reinaldo Amorim de. ABC das Alagoas: dicionário biobibliográfico, histórico e geográfico das Alagoas. Brasília: Senado Federal, Conselho Editorial, 2005. 2 v.

BECKER, Colette. Le discours d'escorte: l'anottation et ses problèmes (à propos de la correspondance de Zola). In: FRANÇON, André; GOYARD, Claude (Orgs.). Les correspondances inédites. Paris: Econômica, 1984. p. 117-129. Ed. bras.: "O discurso de escolta: as notas e seus problemas (o exemplo da correspondência de Zola)". Trad. de Ligia Fonseca Ferreira. Patrimônio e Memória, São Paulo, Unesp, v. 9, n. 1, p. 144-56, jan./jun. 2013.

BOSI, Alfredo. Reflexões sobre a arte. 4. ed. São Paulo: Ática, 1991.

CARPEAUX, Otto Maria. Tendências do moderno romance brasileiro (1948). In: Ensaios reunidos 1946-1971. v. II. Prefácio de Ivan Junqueira. Rio de Janeiro: UniverCidade \& Topbooks, 2005, p. 362-367.

DIAZ, José-Luis. Qual genética para as correspondências? Tradução de Cláudio Hiro e Maria Sílvia Ianni Barsalini. Manuscrítica: revista de Crítica Genética, 15. São Paulo: Associação de Pesquisadores de Crítica Genética/Humanitas, 2007. p. 119-162.

FARGE, Arlette. O sabor do arquivo. Tradução de Fátima Murad. São Paulo: Edusp, 2009.

MORAES, Marcos Antonio de. Edição da Correspondência reunida de Mário de Andrade: histórico e alguns pressupostos. Patrimônio e Memória, UNESP/Assis - On-line, v. 4, p. 1-14, jun. 2009.

RAMOS, Graciliano. Angústia. 7. ed. Rio de Janeiro: José Olympio, 1955.

RAMOS, Graciliano. Carta a Aloísio Branco. Maceió, 16 out. 1931. Apud ROCHA, Tadeu. Modernismo e regionalismo. Maceió: Departamento Estadual de Cultura, 1964. p. 72.

RAMOS, Graciliano. Carta a Caio Prado Júnior. Rio de Janeiro, 12 mar. 1949. Arquivo Caio Prado Júnior, IEB-USP.

RAMOS, Graciliano. Carta a José Tobias Filho. Rio de Janeiro, 21 nov. 1914. Série Correspondência Ativa, Arquivo Graciliano Ramos, IEB-USP.

RAMOS, Graciliano. Carta a Serafín Garcia. Rio de Janeiro, 13 out. 1943. Série Correspondência Ativa, Arquivo Graciliano Ramos, IEB-USP. 
RAMOS, Graciliano. Carta a Serafín J. García. Rio de Janeiro, 12 nov. 1945. Série Correspondência Ativa, Arquivo Graciliano Ramos, IEB-USP.

RAMOS, Graciliano. Carta aos Srs. Livschitz \& Morosoli. Rio de Janeiro, 17 jul. 1945. Série Correspondência Ativa, Arquivo Graciliano Ramos, IEB-USP.

RAMOS, Graciliano. Cartas. Rio de Janeiro: Record, 1980 (Edição especial; MPM-Comunicações); 7. ed. (aumentada). Rio de Janeiro: Record, 1992. 8. ed., 2011.

RAMOS, Graciliano. Cartas inéditas de Graciliano Ramos a seus tradutores argentinos Benjamín de Garay e Raúl Navarro. Introdução, ensaios e notas de Pedro Moacir Maia; organização e apresentação de Fernando da Rocha Peres. Salvador: EDUFBA, 2008.

RAMOS, Graciliano. Contos e novelas. Rio de Janeiro: Livraria-Editora da Casa do Estudante do Brasil, 1957. 3 v. (Norte e Nordeste; Leste; Sul e Centro-oeste); Seleção de contos brasileiros. Rio de Janeiro: Edições de Ouro, 1966. 3 v. (Norte e Nordeste; Leste; Sul e Centro-oeste)

RAMOS, Graciliano. Correspondência ativa, passiva e de terceiros - Arquivo Graciliano Ramos - Instituto de Estudos Brasileiros da Universidade de São Paulo, IEB-USP. Doado em 1980 por Heloísa Ramos.
RAMOS, Graciliano. Decadência do romance brasileiro. Literatura, Rio de Janeiro, ano I, n. 1, set. 1946. Apud GARBUGLIO, J. C. et al. Graciliano Ramos. São Paulo: Ática, 1987, p. 114-116; Garranchos: textos inéditos de Graciliano Ramos. Org. Thiago Mio Salla. Rio de Janeiro: Record, 2012, p. 262-267; ed. uruguaia: Decadencia de la novela brasileña. Nueva Gazeta, Montevidéo, n. 11, dez. 1941 (Cf. CARPEAUX, Otto Maria. Pequena bibliografia crítica da literatura brasileira. Rio de Janeiro: Edições de Ouro, 1968, p. 256).

RAMOS, Graciliano. Infância. 3. ed. Rio de Janeiro: José Olympio, 1953.

RAMOS, Graciliano. S. Bernardo. 6. ed. Rio de Janeiro: José Olympio, 1955.

REVISTA Novidade. (Direção de Valdemar Cavalcanti e Alberto Passos Guimarães). Maceió, Livraria Vilas-Boas, 1931, 24 números.

SODRÉ, Nélson Werneck. Memórias de um escritor. Rio de Janeiro: Civilização Brasileira, 1970. v. 1.

Recebido: 28 de outubro de 2013

Aprovado: 06 de janeiro de 2014

Contato: biolito@gmail.com 